\title{
Update on the Hong Kong Reference Framework for Hypertension Care for Adults in Primary Care Settings - review of evidence on the definition of high blood pressure and goal of therapy
}

\author{
MK Lim, Stanley CN Ha, KH Luk *, WK Yip, Caroline SH Tsang, Martin CS Wong
}

This article was published on 3 Jan 2019 at www.hkmj.org.

\section{A B S T R A C T}

The Hong Kong Reference Framework for Hypertension Care for Adults in Primary Care Settings is updated regularly to ensure it reflects the latest medical development and best practice. In 2017, guidelines from the United States included a major change, adopting the lower blood pressure values of $130 / 80 \mathrm{~mm} \mathrm{Hg}$ in defining hypertension, in contrast to the prevailing international consensus of $140 / 90 \mathrm{~mm} \mathrm{Hg}$. After thorough review of the literature and international guidelines, the Advisory Group on Hong Kong Reference Framework for Care of Diabetes and Hypertension in Primary Care Settings (Advisory Group) recommends that the definition of hypertension adopted in the Reference Framework should remain unchanged as a blood pressure of $\geq 140 / 90 \mathrm{~mm} \mathrm{Hg}$, as there is currently inadequate evidence and lack of general consensus to support such change in Hong Kong. The Advisory Group agrees on individualised treatment goals, and recommends that the initial blood pressure goal for individuals with uncomplicated hypertension should be $<140 / 90 \mathrm{~mm} \mathrm{Hg}$; for those who can tolerate it, the goal should be $\leq 130 / 80 \mathrm{~mm} \mathrm{Hg}$. A lower blood pressure is advisable for young or overweight/ obese patients, smokers, and patients with other cardiovascular risk factors.

\section{Hong Kong Med J 2019;25:64-7}

https://doi.org/10.12809/hkmj187701

${ }^{1}$ MK Lim, MB, BS, FHKAM (Family Medicine)

${ }^{1} \mathrm{SCN} \mathrm{Ha}, \mathrm{BSc}, \mathrm{MPH}$

${ }^{1}$ KH Luk *, MB, BS, FHKAM (Family Medicine)

${ }^{1}$ WK Yip, MB, ChB, FHKAM (Family Medicine)

CSH Tsang, MB, ChB, FHKAM (Community Medicine)

${ }^{2}$ MCS Wong, MD, FHKAM (Family Medicine)

Primary Care Office, Department of Health, Hong Kong

2 Advisory Group on Hong Kong Reference Framework for Care of

Diabetes and Hypertension in Primary Care Settings, Hong Kong

* Corresponding author: kam_hung_luk@dh.gov.hk

\section{Introduction}

Hypertension is an important cardiovascular risk factor and the commonest chronic disease in Hong Kong, with a prevalence of $27.7 \%$ among people aged $\geq 15$ years. ${ }^{1}$ The Primary Care Office of the Department of Health first published the Hong Kong Reference Framework for Hypertension Care for Adults in Primary Care Settings (Reference Framework) in 2010. ${ }^{2}$ Drawing on international evidence of best practice, the Reference Framework provides an evidence-based reference to primary healthcare professionals in the identification and management of hypertension in Hong Kong. To ensure the Reference Framework reflects latest medical development and evidence, it is updated regularly with expert advice from the Advisory Group on Hong Kong Reference Framework for Care of Diabetes and Hypertension in Primary Care Settings (Advisory Group). The Advisory Group comprises representatives from academia, relevant Colleges of the Hong Kong Academy of Medicine, and professional organisations.

In 2017, the American College of Cardiology (ACC) and the American Heart Association (AHA) released guideline recommendations using lower blood pressure (BP) values to define hypertension as systolic $\mathrm{BP}(\mathrm{SBP}) \geq 130 \mathrm{~mm} \mathrm{Hg}$ and/or diastolic $\mathrm{BP}(\mathrm{DBP}) \geq 80 \mathrm{~mm} \mathrm{Hg}{ }^{3}$ This recommendation is in contrast to the prevailing consensus of SBP $\geq 140$ $\mathrm{mm} \mathrm{Hg}$ and/or DBP $\geq 90 \mathrm{~mm} \mathrm{Hg}$ adopted by the World Health Organization and other international guidelines. ${ }^{4}$ The BP goal of hypertensive therapy was also lowered to $<130 / 80 \mathrm{~mm} \mathrm{Hg}$ in the new ACC/ AHA guideline. ${ }^{3}$ It is foreseeable that these new recommendations would arouse concern regarding the diagnosis and management of hypertension at individual patient care level, as well as issues related to disease labelling, changes in epidemiology, and the applicability of these recommendations to other populations. Even within the United States, the recommendations in this guideline were not unanimouslyagreed with among different authorities, and the application of these recommendations remains controversial. ${ }^{5,6}$ There is also little understanding of how these recommendations translate to non-United States populations, and there is currently no general consensus on the adoption of these recommendations in Hong Kong. 
The aim of this study was to review the relevant literature, discuss the benefits and potential harms of setting lower BP values in the diagnosis and management of hypertension, and suggest updated recommendations on care for individuals with uncomplicated hypertension in the context of the primary care settings in Hong Kong.

\section{What does the current evidence say?}

\section{Benefits of a lower blood pressure definition and treatment goal}

Hypertension is a well-known modifiable risk factor for cardiovascular disease. It is associated with a number of adverse outcomes such as stroke, myocardial infarction, heart failure, peripheral artery disease, end-stage renal disease, and premature death. ${ }^{7}$ Meta-analyses of observational prospective studies suggested that people with SBP 120 to 139 $\mathrm{mm} \mathrm{Hg}$ and/or DBP 80 to $89 \mathrm{~mm} \mathrm{Hg}$ may also be at risk of cardiovascular events. ${ }^{8-17}$ For this group of people, it was observed that the higher the BP was, the higher the cardiovascular risk was, in general. However, the risk was less significant and less clearly established in Asians, except for the risk of stroke which was shown to be lower, similar to, or even higher than that for non-Asians from different metaanalyses. ${ }^{8-17}$ The benefit of lowering BP to $<140 / 90$ $\mathrm{mm} \mathrm{Hg}$ is well established. A meta-analysis showed that, when compared with treatment with a mean BP goal of 140/81 mm Hg, more intensive treatment with a lower mean BP goal of $133 / 76 \mathrm{~mm} \mathrm{Hg}$ provided additional benefits on reducing the risk of major cardiovascular events, myocardial infarction, stroke, and albuminuria. ${ }^{18}$ However, although it was shown that treatment with a BP goal of $<140 / 90 \mathrm{~mm}$ $\mathrm{Hg}$ lowered cardiovascular risk in general, further reductions in $\mathrm{BP}$ may further reduce the risk only of stroke. ${ }^{19}$ This relationship between $\mathrm{BP}$ values and the risk of stroke is also seen in the Chinese population. A study involving 17720 Chinese uncomplicated hypertensive adults concluded that an SBP goal of 120 to $130 \mathrm{~mm} \mathrm{Hg}$ resulted in the lowest risk of first stroke. ${ }^{20}$

Since the above findings were mostly from meta-analyses based on observational prospective studies, it may be worthwhile to have a brief discussion on the SPRINT ${ }^{21}$ trial and the ACCORD ${ }^{22}$ trial, which were the two major randomised controlled trials on lower BP goals. The participant characteristics were different in these two trials; SPRINT involved hypertensive patients with increased cardiovascular risk but no history of diabetes mellitus or stroke, whereas ACCORD included patients with type 2 diabetes mellitus. ${ }^{21,22}$ Both trials compared the clinical outcomes and adverse events in an intensive treatment group
「香港高血壓參考概覽一一成年高血壓患者在 基層醫療的護理」：高血壓定義及治療目標的 實證檢視

林武健、夏正楠、陸金雄、葉榮基、曾守衡、黃至生

$\ulcorner$ 香港高血壓參考概覽一一成年高血壓患者在基層醫療的護理」會定 期進行更新, 以反映最新的醫學發展及最佳的實踐方法。於 2017 年, 有美國指引把高血壓定義值降低至 $130 / 80 \mathrm{~mm} \mathrm{Hg}$, 這有別於國際間 普遍採納的共識 $140 / 90 \mathrm{~mm} \mathrm{Hg}$ 。香港基層醫療的糖尿病及高血壓參 考概覽諮詢小組（諮詢小組）經過詳細檢視文獻及國際間指引後, 認 為未有足夠實證及共識支持於本地改動高血壓定義, 因此建議參考概 覽內所採納的高血壓定義值保持不變（即 140/90 mm Hg 或以上）。 諮詢小組亦認同個人化的高血壓治療目標, 建議沒有併發症的高血壓 患者的初期治療目標應為 $140 / 90 \mathrm{~mm} \mathrm{Hg}$ 以下; 對於耐受性良好的患 者, 其目標血壓應為 $130 / 80 \mathrm{~mm} \mathrm{Hg}$ 或以下。若高血壓患者屬年輕、 超重 / 肥胖、吸煙或有其他心血管疾病風險因素, 亦建議將血壓控制 於較低水平

(SBP $<120 \mathrm{~mm} \mathrm{Hg}$ ) and a standard treatment group (SBP $<140 \mathrm{~mm} \mathrm{Hg}$ ). The results regarding the primary outcome were different in the two trials. The SPRINT trial concluded that the intensive BPlowering treatment significantly lowered rates of heart failure, fatal major cardiovascular events, and all-cause mortality. ${ }^{21}$ In contrast, the ACCORD trial failed to demonstrate such cardiovascular benefits in the intensive treatment group. The ACCORD trial concluded that intensive BP-lowering treatment did not reduce the rate of the primary composite outcomes of fatal and non-fatal major cardiovascular events. ${ }^{22}$

There was concern regarding the use of unattended automated office BP in the SPRINT trial; automated office BP had not been used in any previous major randomised controlled trials (such as ACCORD) on BP-lowering treatment. ${ }^{23}$ When compared with conventional office BP measurement, automated office BP may result in lower BP values due to the absence of the white-coat effect. Therefore, it has been suggested that the BP values reported in SPRINT may actually correspond to conventional office SBPs of 130 to $140 \mathrm{~mm} \mathrm{Hg}$ and 140 to 150 $\mathrm{mm} \mathrm{Hg}$ in the more intensive and less intensive BPlowering treatment groups, respectively. ${ }^{7}$ It is unclear if these findings can be extrapolated to hypertensive patients in Hong Kong.

\section{Potential harm of a lower blood pressure definition and treatment goal}

In both SPRINT and ACCORD trials, significantly higher rates of adverse events were observed in patients treated with lower BP goals (ie, the intensive treatment group). In these groups, patients used a larger average number of antihypertensive 
medications than those in the standard treatment group. The recorded adverse events included hypotension, electrolyte abnormality, and acute kidney injury. ${ }^{21,22}$ Recent systemic reviews and metaanalyses have proposed that intensive BP-lowering treatment increases the risk of cardiovascular death without observable benefits; these studies have concluded that there is insufficient evidence to justify the lower BP goal. ${ }^{24-26} \mathrm{~A}$ large retrospective cohort study in Hong Kong, which involved around 100000 Chinese patients with diabetes mellitus receiving primary care services, identified that the SBP range for the lowest risk of cardiovascular diseases and allcause mortality was 130 to $134 \mathrm{~mm} \mathrm{Hg}$. In addition, a J-curve relationship between SBP and all outcomes of fatal and non-fatal cardiovascular diseases was observed, and patients with SBP $<125 \mathrm{~mm} \mathrm{Hg}$ were found to have significantly higher hazard ratio to all composite outcomes. ${ }^{27}$

Isolated systolic hypertension-an elevation in SBP but not DBP-is prevalent in older adults. ${ }^{28,29}$ Because interventions that lower SBP also reduce DBP, intensive SBP reduction in patients with isolated systolic hypertension may also result in lower values of DBP. Low DBP is associated with increased risk of target-organ hypoperfusion and cardiovascular events. ${ }^{28-30}$ For example, most ventricular myocardial perfusion occurs during diastole; therefore, a lower DBP could potentially lead to myocardial hypoperfusion and associated damage, especially in individuals with left ventricular hypertrophy or coronary artery disease. ${ }^{30}$ It has also been suggested that low DBP is associated with an increase in allcause mortality. ${ }^{31}$

\section{Recommendation}

\section{Definition of high blood pressure}

The Advisory Group regularly reviews the latest scientific evidence and recommendations from different professional organisations. The Advisory Group has noticed that there is currently inadequate evidence and lack of general consensus to support a change to the definition of hypertension in Hong Kong. Therefore, the Advisory Group agreed that the Reference Framework definition of hypertension should remain unchanged as a $B P$ of $\geq 140 / 90 \mathrm{~mm} \mathrm{Hg}$.

\section{Goal of therapy for hypertensive patients}

Hypertensive patients are known to have a higher cardiovascular risk if they have other risk factors such as smoking, obesity, sedentary lifestyle, or elevated lipids or glucose; hence, a global risk approach should be included in assessing the cardiovascular risk of an individual patient. ${ }^{32}$ Although some evidence has suggested that a lower BP may provide greater benefit for patients with higher cardiovascular risk, there is also an increased risk of treatment noncompliance and serious adverse events from treatment if the BP is pushed too low, especially in older patients. It is, therefore, appropriate to determine the treatment goal on an individual basis after balancing the benefits and potential harms of having a lower BP goal in the context of that individual. Taking these into account, the Advisory Group endorses the approach of setting the BP goal with the consideration of age, underlying cardiovascular risk factors, and tolerability to treatment of the individual patient, instead of a single BP goal for all patients. This approach echoes the recommendation of recently published international guidelines. ${ }^{7}$ The Advisory Group recommends that the initial BP goal of therapy for individuals with uncomplicated hypertension should be $<140 / 90 \mathrm{~mm} \mathrm{Hg}$; and for individuals who can tolerate it, the BP goal should be $\leq 130 / 80 \mathrm{~mm} \mathrm{Hg}$. A lower BP is advisable for young or overweight/obese patients, smokers, and patients with other cardiovascular risk factors.

\section{Conclusion}

Hypertension is an important cardiovascular risk factor and the commonest chronic disease in Hong Kong. Primary care physicians play an important role in the early diagnosis, prompt assessment and proper management of hypertension. The Reference Framework aims to provide updated evidencebased recommendations to support and influence the current practice of primary care physicians in Hong Kong, and to reduce the burden of long-term cardiovascular sequelae for hypertensive patients.

\section{Author contributions}

All authors have contributed to the concept or design of this study, acquisition of data, analysis or interpretation of data, drafting of the manuscript, and critical revision for important intellectual content. All authors had full access to the data, contributed to the study, approved the final version for publication, and take responsibility for its accuracy and integrity.

\section{Acknowledgements}

We would like to thank the members of the Advisory Group for their invaluable contributions in the development and update of the Reference Framework.

\section{Conflicts of interest}

As an editor of the journal, MCS Wong was not involved in the peer review process. All other authors have disclosed no conflicts of interest.

\section{Funding/support}

This research received no specific grant from any funding agency in the public, commercial, or not-for-profit sectors.

\section{References}

1. Centre for Health Protection, Department of Health, Hong 
Kong SAR Government. Report of Population Health Survey 2014/2015. Available from: https://www.chp.gov. hk/en/static/51256.html. Accessed 15 Oct 2018.

2. Primary Care Office, Department of Health, Hong Kong SAR Government. Hong Kong Reference Framework for Hypertension Care for Adults in Primary Care Settings. Revised edition 2018. Available from: https://www.pco. gov.hk/english/resource/professionals_hypertension_pdf. html. Accessed 15 Oct 2018.

3. Whelton PK, Carey RM, Aronow WS, et al. 2017 ACC/ AHA/AAPA/ABC/ACPM/AGS/APhA/ASH/ASPC/ NMA/PCNA Guideline for the Prevention, Detection, Evaluation, and Management of High Blood Pressure in Adults: Executive Summary: A Report of the American College of Cardiology/American Heart Association Task Force on Clinical Practice Guidelines. J Am Coll Cardiol 2018;71:2199-269.

4. Whitworth JA; World Health Organization, International Society of Hypertension Writing Group. 2003 World Health Organization (WHO)/International Society of Hypertension (ISH) statement on management of hypertension. J Hypertens 2003;21:1983-92.

5. Wilt TJ, Kansagara D, Qaseem A; Clinical Guidelines Committee of the American College of Physicians. Hypertension limbo: balancing benefits, harms, and patient preferences before we lower the bar on blood pressure. Ann Intern Med 2018;168:369-70.

6. Crawford C. AAFP decides to not endorse AHA/ACC Hypertension Guideline: Academy continues to endorse JNC8 Guideline. Available from: https://www.aafp.org/ news/health-of-the-public/20171212notendorseahaaccgdlne.html. Accessed 8 Oct 2018.

7. Williams B, Mancia G, Spiering W, et al. 2018 ESC/ESH Guidelines for the management of arterial hypertension: The Task Force for the management of arterial hypertension of the European Society of Cardiology and the European Society of Hypertension. J Hypertens 2018;36:19532041.

8. Guo X, Zhang X, Guo L, et al. Association between prehypertension and cardiovascular outcomes: a systematic review and meta-analysis of prospective studies. Curr Hypertens Rep 2013;15:703-16.

9. Guo X, Zhang X, Zheng L, et al. Prehypertension is not associated with all-cause mortality: a systematic review and meta-analysis of prospective studies. PLoS One 2013;8:e61796.

10. Huang Y, Cai X, Li Y, et al. Prehypertension and the risk of stroke: a meta-analysis. Neurology 2014;82:1153-61.

11. Huang Y, Cai X, Liu C, et al. Prehypertension and the risk of coronary heart disease in Asian and Western populations: a meta-analysis. J Am Heart Assoc 2015;4.pii:e001519.

12. Huang Y, Cai X, Zhang J, et al. Prehypertension and incidence of ESRD: a systematic review and meta-analysis. Am J Kidney Dis 2014;63:76-83.

13. Huang Y, Su L, Cai X, et al. Association of all-cause and cardiovascular mortality with prehypertension: a metaanalysis. Am Heart J 2014;167:160-8.e1.

14. Huang Y, Wang S, Cai X, et al. Prehypertension and incidence of cardiovascular disease: a meta-analysis. BMC Med 2013;11:177.

15. Lee M, Saver JL, Chang B, Chang KH, Hao Q, Ovbiagele B. Presence of baseline prehypertension and risk of incident stroke: a meta-analysis. Neurology 2011;77:1330-7.

16. Shen L, Ma H, Xiang MX, Wang JA. Meta-analysis of cohort studies of baseline prehypertension and risk of coronary heart disease. Am J Cardiol 2013;112:266-71.

17. Wang $\mathrm{S}$, Wu H, Zhang Q, Xu J, Fan Y. Impact of baseline prehypertension on cardiovascular events and all-cause mortality in the general population: a meta-analysis of prospective cohort studies. Int J Cardiol 2013;168:4857-60.

18. Xie X, Atkins E, Lv J, et al. Effects of intensive blood pressure lowering on cardiovascular and renal outcomes: updated systematic review and meta-analysis. Lancet 2016;387:435-43.

19. Thomopoulos C, Parati G, Zanchetti A. Effects of blood pressure lowering on outcome incidence in hypertension: 2. Effects at different baseline and achieved blood pressure levels-overview and meta-analyses of randomized trials. J Hypertens 2014;32:2296-304.

20. Fan F, Yuan Z, Qin X, et al. Optimal systolic blood pressure levels for primary prevention of stroke in general hypertensive adults: findings from the CSPPT (China Stroke Primary Prevention Trial). Hypertension 2017;69:697-704.

21. SPRINT Research Group, Wright JT Jr, Williamson JD, et al. A randomized trial of intensive versus standard bloodpressure control. N Engl J Med 2015;373:2103-16.

22. ACCORD Study Group, Cushman WC, Evans GW, et al. Effects of intensive blood-pressure control in type 2 diabetes mellitus. N Engl J Med 2010;362:1575-85.

23. Kjeldsen SE, Lund-Johansen P, Nilsson PM, Mancia G. Unattended blood pressure measurements in the systolic blood pressure intervention trial: implications for entry and achieved blood pressure values compared with other trials. Hypertension 2016;67:808-12.

24. Saiz LC, Gorricho J, Garjón J, Celaya MC, Erviti J, Leache L. Blood pressure targets for the treatment of people with hypertension and cardiovascular disease. Cochrane Database Syst Rev 2018;(7):CD010315.

25. Garrison SR, Kolber MR, Korownyk CS, McCracken RK, Heran BS, Allan GM. Blood pressure targets for hypertension in older adults. Cochrane Database Syst Rev 2017;(8):CD011575.

26. Brunström M, Carlberg B. Effect of antihypertensive treatment at different blood pressure levels in patients with diabetes mellitus: systematic review and meta-analyses. BMJ 2016;352:i717.

27. Wan EY, Yu EY, Fung CS, et al. Do we need a patientcentered target for systolic blood pressure in hypertensive patients with type 2 diabetes mellitus? Hypertension 2017;70:1273-82.

28. Pinto E. Blood pressure and ageing. Postgrad Med J 2007;83:109-14.

29. Bavishi C, Goel S, Messerli FH. Isolated systolic hypertension: an update after SPRINT. Am J Med 2016;129:1251-8.

30. Beddhu S, Chertow GM, Cheung AK, et al. Influence of baseline diastolic blood pressure on effects of intensive compared with standard blood pressure control. Circulation 2018;137:134-43.

31. Tringali S, Oberer CW, Huang J. Low diastolic blood pressure as a risk for all-cause mortality in VA Patients. Int J Hypertens 2013;2013:178780.

32. World Health Organization. Prevention of cardiovascular disease. Guidelines for assessment and management of cardiovascular risk. Available from: http://www.who. int/cardiovascular_diseases/guidelines/Full\%20text.pdf. Accessed 12 Oct 2018. 